\title{
DESFECHOS TRÁGICOS E REFERÊNCIAS EXPRESSIONISTAS NAS TRAGÉDIAS CARIOCAS DE NELSON RODRIGUES
}

O presente artigo propõe uma leitura do ciclo denominado tragédias cariocas, conjunto de oito peças escritas pelo dramaturgo Nelson Rodrigues entre 1953 e 1978, com o objetivo de analisar em que sentido os desfechos de malogro das personagens rodriguianas se aproximam de recursos expressionistas empreendidos pelo dramaturgo em alguns textos.

Palavras-chave: Nelson Rodrigues, tragicidade, expressionismo.

\section{Abstract}

This paper's proposal is to study the cycle entitled "carioca tragedies", a group of eight plays written by Nelson Rodrigues between 1953 and 1978. The aim is to analyse how the unsuccessful outcomes of the rodriguian characters are similar to expressionist elements used by the playwright in some texts.

Keywords: Nelson Rodrigues, tragic, expressionism. 


\section{Uma breve introdução}

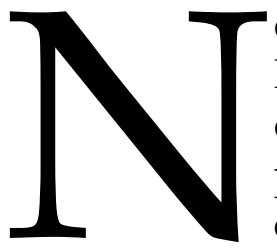

o teatro de Nelson Rodrigues, pode-se observar a constante presençadepersonagens que, ao reprimir um impulso - em sua grande maioria, de ordem sexual -, entram em conflito com a instituição que lhes impõe a determinadas regras. Essas instituições sociais podem ser identificadas como a família, a igreja ou o trabalho. No desenvolvimento do enredo, as personagens, impulsionadas pelo conflito constante, resolvem liberar seus "estranhamentos" sexuais, o que causará inevitavelmente um rompimento de regras e tabus para, em seguida, elas sofrerem as consequências dessa liberação de seus desejos. A partir da revelação do desejo, o enredo sofre um golpe de teatro e acompanhamos a derrocada sobretudo das protagonistas. Esses danos - o malogro das personagens - em geral coincidem com o desfecho dos acontecimentos; exatamente no momento em que temos no resultado a consequência da liberação dos desejos das personagens, é o momento em que a história se encerra, dentro de uma linearidade de tempo.Háumgrandenúmerodepeças deste dramaturgo cujo enredo é alinear, contado através de flashbacks. Por isso, muitas vezes, os momentos mais trágicos antecipam o final da peça e não necessariamente se coincidem. Esse desfecho trágico ao qual me refiro não necessariamente é a morte da protagonista ou das personagens - e nem sempre atinge a todas elas.

\section{Acerca do expressionismo}

No Brasil, apenas alguns autores sofreram influências, e limitadas, do expressionismo, até porque não se pode

1 Doutora em Teoria e História Literária pela UNICAMP. Desenvolveu, no mestrado e doutorado, pesquisa sobre a dramaturgia de Nelson Rodrigues. É membro-fundador do Grupo de Estudos em Dramaturgia Letra e Ato, vinculado Departamento de Artes Cênicas da UNICAMP. afirmar a existência efetiva de um autor expressionista aqui (LIMA, 2002). ${ }^{2}$ Em Nelson Rodrigues, é perceptível uma maior influência expressionista nas peças míticas, com suas deformações, a violência com que se dirigem ao público, a maneira agressiva como reagem a situações sociais, principalmente no que diz respeito a situações que envolvem a camada burguesa da sociedade. Robert Bledsoe (1971), inclusive, defende a existência do ciclo expressionista em Nelson Rodrigues, que compreende cinco peças: Vestido de noiva, Álbum de família, Anjo negro, Dorotéia e Senhora dos afogados.

Quando escreveu as tragédias cariocas, o dramaturgo saiu do campo mítico de representação e se voltou para um olhar da sociedade mais colado à realidade. Nessa transição, ele deixou para trás muitos dos meios representativos expressionistas. Mas, por pouco que seja, ainda assim restaram alguns traços dessa estética eminentemente alemã. Os resquícios expressionistas nas peças aqui em questão parecem estar ligados ao desfecho, ainda que algumas delas contenham uma especificidade expressionista mais evidente em outros momentos.

Segundo Casals (s.d.), Fraga (1998), Palmier (1979), dentre outros, o expressionismo não chegou a se constituir um movimento propriamente dito, estruturado e com doutrina definida. Foi antes uma atmosfera confusa, que se manifestou principalmente na Alemanha, uma expressão artística que foi capaz de transformar a vida cultural alemã em todas as suas manifestações.

Para Jean-Michel Palmier, o expressionismo não é original em sua forma ou em seu estilo, mas sim na maneira de tratá-los. Isso confirma a ideia de que tal manifestação não tinha uma formação clara e objetiva, mas era uma arte subjetiva.

2 O bailado do Deus morto, de Flávio de Carvalho, cuja estreia ocorreu em 1933, é considerada uma peça expressionista. Ela foi escrita às pressas para a inauguração do Teatro da Experiência e, segundo Lima (2002), teve sua importância bastante relativizada, pois chegou tarde e foi logo esquecida. 
O que o expressionismo faz, explica Eudinyr Fraga, é antepor o feio, o banal, o escabroso, sobrepondo-os à beleza. Em uma primeira análise, grosso modo, podese afirmar que essas características são facilmente encontradas na dramaturgia de Nelson, uma vez que o feio e o banal estão presentes em suas peças, inclusive nas tragédias cariocas. Por outro lado, há um distanciamento do expressionismo nestas peças se outro aspecto dessa estética for desvelado: na encenação expressionista, trabalha-se a deformação também da interpretação e da significação visual e auditiva (FRAGA, 1998). Daí o palco ser o espaço interno de uma consciência, onde o protagonista tem uma real existência, mas as outras personagens são suas projeções exasperadas. Bem sabemos que essa é uma característica de algumas peças, em especial Vestido de noiva e Valsa $n^{0}$ 6, mas não se enquadra em qualquer peça do último ciclo dessa dramaturgia.

Um dos elementos mais salientes na dramaturgia rodriguiana é a maneira como são apontados momentos do quotidiano, que se destacam por se aproximarem do tom grotesco. Seja uma personagem que tira um cravo do nariz, um garoto que permanece o tempo todo com o dedo no nariz, um casal que disputa o banheiro ou a filha que aparece na frente do pai em trajes de lingerie, são todas situações que chamam a atenção pela forma disforme como são postas em cena. De certa forma, essa relação com o grotesco é um traço bastante característico da estética expressionista:

A realidade projetada a partir ou em função dessas consciências reduzidas às linhas mais elementares, visto o excesso emocional, a pressão das condições e o fervor profético não permitirem requintes e nuanças, apresenta forçosamente distorções violentas, traços caricaturais, desproporções e deformações grotescas. O que importava aos expressionistas não foi a beleza ou harmonia da obra e sim a força expressiva. (...) Pelo excesso hiperbólico na descrição do asqueroso tenta-se exprimir a decomposição da sociedade e o absurdo das condições reinantes. (ROSENFELD, 1993, p. 285).
Voltados para a subjetividade, os artistas expressionistas retratam um conflito, levado ao limite em decorrência do confronto violento entre valores estabelecidos pelas autoridades e as vítimas das convenções do poder. É desse modo que o instinto, por muito tempo aprisionado, tem triunfo momentâneo. Porém, esse instinto logo depois leva a personagem (no caso do teatro expressionista) ao aniquilamento. A dramaturgia rodriguiana passa por processo semelhante: há uma tendência à destruição após um aparente triunfo dos desejos.

Casals explica que Nietzsche foi uma grande influência para o expressionismo, pois foi ele quem certificou a morte de Deus, libertando o homem das sombras que esta figura projeta sobre ele. Assim, a partir da morte de Deus, morre também a moral e nasce Dioniso; seu reinado restabelece a relação entre o instinto e a consciência. $\mathrm{O}$ primeiro, força de afirmação e criação, é a vida. $\mathrm{O}$ último, a consciência, é a faculdade de negação, a morte. $\mathrm{Na}$ esteira desse pensamento, pode-se afirmar que esses dois polos perpassam genericamente a obra rodriguiana, sem poder, no entanto, dizer que exista consciência nas personagens rodriguianas. Assim, os momentos em que as personagens seguem seus instintos são as situações de felicidade (embora momentânea) desvelada; a partir do momento em que o torpor causado pela revelação de seus desejos passa, surge o fator negativo, em muitos casos, a própria morte.

\section{Desfechos trágicos}

Ironia e sarcasmo, recursos provocadores do riso, são elementos recorrentes na dramaturgia de Nelson Rodrigues. Por trás desse sarcasmo, há um tom de denúncia das hipocrisias, mentiras, falcatruas e desejos, responsáveis pelo desenvolvimento da trama até desencadear em um desfecho de derrocada. Esse caminho percorrido, da relação causa e 
efeito, é especialmente apreciado pela obra de caráter expressionista. De uma forma ou de outra, se nem todas as peças de Nelson têm algum caráter expressionista, elas carregam consigo, ainda assim, o uso deliberado de certo sentido do trágico. Vejamos como isso acontece efetivamente nos textos.

Geni, protagonista de Toda nudez será castigada, narra os acontecimentos de sua vida através de uma fita cassete, deixada para Herculano, seu marido. Ao iniciar a peça, ela está morta e tudo o que se passa no palco é a representação em flashback dos fatos narrados. $\mathrm{O}$ caminho de destruição da personagem começa muito antes, mas só acontece o aniquilamento total com o seu suicídio, já que ele é realizado depois de Geni atravessar por um processo de prostração. A morte, aqui, é o resultado de um longo período de frustrações e derrotas.

Instigada por Patrício, irmão de Herculano, Geni se apaixona pelo viúvo e se utiliza da chantagem como artifício para que ele se case com ela. No entanto, encontra em Serginho a inviabilidade de seu casamento, já que o filho de Herculano é contra qualquer união do pai com outra mulher. Algumas artimanhas, avanços e recuos que encaminham a ação acontecem ainda nos dois primeiros atos. Manipulada por Patrício, Geni exige o casamento com Herculano, que, para conseguir efetivá-lo, tenta convencer seu filho a ir para a Europa. No entanto, sua tentativa é barrada pelas tias, que não aceitam a separação do sobrinho. No final do segundo ato, Serginho se envolve em uma briga e, na prisão, é violentado. Com isso, há um golpe de teatro e os fatos mudam de direção. Posteriormente, Geni se apaixona por Serginho e, em condição imposta pelo próprio garoto, aceita se unir a Herculano para ficar ao lado do enteado. Após casar-se com Herculano, Geni tornase amante do próprio enteado e, ao saber que ele foi embora com o ladrão boliviano, que o violentou na prisão, ela se mata, mas antes resolve contar toda a verdade para o marido:
(Voz gravada de Geni.)

GENI - Teu filho fugiu, sim, com o ladrão boliviano. Foram no mesmo avião, no mesmo avião. Estou só, vou morrer só. (Num rompante de ódio) Não quero meu nome no túmulo! Não ponham nada! (Exultante e feroz) E você, velho corno! Maldito você! Maldito o teu filho, e essa família só de tias. (Num riso de louca) Lembranças à tia machona! (Num último grito) Malditos também os meus seios!

(A voz de Geni se quebra num soluço. Acaba a gravação. Sons de fita invertida. Iluminada apenas a cama vazia.) (RODRIGUES, 1990, p. 238)

Herculano, outra personagem que tem em si o caráter trágico, depara-se com a destruição de suas ilusões quando ouve, da própria esposa, todos os seus infortúnios. Logo no início, Herculano chega em casa procurando pela esposa, aparentemente feliz. Mas, ao ouvir as declarações pela fita cassete, ele se depara com sua total ignorância e desdita. Patrício consegue, por meio de Geni e de Serginho, conduzir o irmão à sua completa aniquilação, pois fez com que ele perdesse a esposa e o filho, destruindo aquilo que Herculano mais prezava. A personagem é um homem católico praticante que não aceita o sexo prazeroso. Ao passar 72 horas com uma prostituta e apaixonar-se por ela, deparase com uma transgressão: o desejo se sobrepõe à crença e ele resolve se casar com a prostituta. Herculano tenta manter um equilíbrio entre seu desejo, representado por Geni, e sua crença, materializada nas tias e em Serginho. Mas esse equilíbrio é quebrado por Patrício, seu irmão, que manipula as situações adversas que lhe acontecem. Quando, finalmente, há uma aparente medida certa em sua vida, ele descobre que tudo não passou de uma ilusão, pois foi enganado por todos. Sua derrocada, assim, acontece lentamente, a cada cena que Geni narra; aos poucos Herculano se depara com a total destruição de seus ideais.

Há, no entanto, outros fatores que evidenciam resquícios expressionistas: os vários momentos do quotidiano retratados 
de forma grotesca, estilo estético quase imperativonessadramaturgia.Porexemplo, em uma discussão de Geni e Herculano, ele se põe de quatro e começa a gritar. Em seguida, a prostituta comenta as varizes da falecida esposa de Herculano. Há aquela tendência ao hiperbólico e ao feio, aspectos caros ao expressionismo e recorrentes no teatro de Nelson Rodrigues. Por outro lado, nota-se a própria temática, que o liga, de alguma forma, ao expressionismo: o sexo. Mas não o sexo puro e simplesmente, mas enquanto um elemento de explosão de fatores psíquicos das personagens. $\mathrm{Ou}$ melhor, a sexualidade das personagens é explorada pelo dramaturgo a ponto de transformá-la em um fator de manifestação súbita da problemática individual de cada um - como um fator de ponto de partida e exploração para o desenrolar da trama.

Otto Lara Resende ou Bonitinha, mas ordinária, ao contrário das outras peças do conjunto, não tem um final essencialmente trágico. Pelo menos no que diz respeito às protagonistas. Edgard e Ritinha revertem a situação decadente que os envolve e conseguem, juntos, fazer com que o amor se sobressaia ao meio lascivo e ganancioso no qual estão inseridos. Em vários momentos da literatura rodriguiana, a máxima do amor superior ao sexo e à ganância é ressaltada. Essencialmente, Nelson Rodrigues ressalta o amor como o sentimento supremo do ser humano, que é corrompido pelo sexo, mas, em situações extremas, vence o sentimento nobre. A diferença nessa peça está essencialmente nas protagonistas, que não são levadas a sua derrocada moral e física. Ao contrário, como em um folhetim romântico, o amor de Edgard e Ritinha vence todos os obstáculos.

Entretanto, antes de qualquer final romântico, a peça é recheada de momentos que poderiam ser encaminhados a um desfecho pouco feliz. Ritinha é uma irmã zelosa com a integridade moral das irmãs mais novas; evidencia em várias cenas a importância dada ao casamento e à virgindade delas, sacrificando-se física e moralmente com a prostituição. Mas eis que todo seu zelo é enfim dissolvido quando as três irmãs são estupradas em uma curra organizada pelo empresário Werneck. Por mais que Werneck ressalte que devolverá a virgindade das meninas com uma rápida intervenção cirúrgica, Edgard questiona se essa "virgindade" interessa:

\footnotetext{
RitinHa - Eu estive com o médico, Edgard. Ele disse. Garantiu. Disse que fica perfeito.

EDGARD - Escuta, Ritinha.

RITINHA (radiante) - Tirei um peso.

EDGARD - Você acha. Escuta. Acha que interessa virgindade assim? Assim, Ritinha?

RitinHA (sem perceber a abjeção moral) Mas o médico, Edgard, disse que o marido não ia perceber, nem ia desconfiar. (IDEM, p. 319)
}

As mortes de Maria Cecília e de Peixoto surgem de maneira estranha e brusca. Não há evidências precedentes à cena da morte que indiquem qualquer tendência a um relacionamento entre Peixoto e sua cunhada. O que pode ser percebido de Maria Cecília é superficial, uma inocência sem tendência a qualquer tipo de perversão. Por outro lado, Peixoto é ambicioso e se auto-denomina canalha, mas não oferece nenhuma evidência de que seja apaixonado pela cunhada. No entanto, a despeito de sua canalhice, no terceiro ato ele tenta mostrar a Edgard como é a família na qual ele está prestes a entrar, a fim de alertá-lo sobre o caráter de Maria Cecília, em uma tentativa de não deixar que Edgard passe a integrar o rol dos corrompidos.

$\mathrm{Na}$ cena em que Peixoto mata Maria Cecília, há uma recorrência à violência e uso do kitsch, o que evidencia uma aproximação com o expressionismo. O primeiro, no intuito de agredir o público apontando para a agressão do quotidiano e da sociedade. Já o outro, está mais ligado ao grotesco, como forma de se sobrepor ao belo, também no intuito de transparecer um aspecto da sociedade.

Boca de Ouro, personagem da peça homônima, é um herói suburbano (ou seria um anti-herói?) descrito de três formas diferentes e pouco se pode afirmar de 
um suposto trajeto percorrido por ele até desembocar no seu final trágico, advindo com a morte. De forma concreta, apenas é possível afirmar que ele é um homem suburbano, banqueiro de jogo do bicho, cuja obsessão maior é o ouro. Na primeira cena da peça, ele pede ao dentista que lhe faça uma dentadura de ouro, em outra recorrência ao kitsh. Da mesma forma, ao longo da ação, ele afirma que está fazendo um caixão de ouro. Outro fato concreto, pela repetição em várias cenas, é que nasceu em uma pia de uma gafieira. Por pura ironia, Boca de Ouro não tem outro destino senão voltar ao ponto de onde partiu: é encontrado morto em uma sarjeta sem a sua maior marca, a dentadura de ouro. Quase um ser mitológico suburbano, como afirmam as rubricas, Boca parte do submundo carioca e permeia a imaginação popular, até encontrar a morte através de uma grã-fina. Enquanto isso, percorre um trajeto do qual a única coisa que se pode afirmar é que foi recheado de assassinatos e manipulações do poder. Tais fatos são conhecidos no decorrer da peça pela narração de D. Guigui, sua ex-amante, que varia a imagem do bicheiro de acordo com o impacto psicológico. Por isso, esse ínterim não pode ser determinado com exatidão devido ao objetivo da peça, que trabalha justamente com a subjetividade da constituição do ser.

Beijo no asfalto, assim como A falecida, segue uma estrutura de drama de estações, na qual o protagonista passa por todas as etapas de sua destruição. Stationendrama, ou drama de estações, é uma estrutura desenvolvida e apreciada pelo expressionismo e da qual Nelson Rodrigues se valeu para desenvolver essas duas tragédias cariocas. Assim, acompanhamos Arandir e Zulmira em várias etapas de seu aniquilamento, aproximando os dois protagonistas em seu destino de desdita, a despeito de tantas outras diferenças entre os dois textos. Arandir, o jovem de Beijo no asfalto, a pedido de um moribundo, o beija na boca no momento de sua morte. Tal atitude é o ponto de partida para um repórter inescrupuloso, Amado Ribeiro, e um delegado, Cunha, tornarem o caso sensacionalista o suficiente para vender jornal. A partir de então, ocorrerá uma série deacontecimentosquelevam Arandiraoseu total isolamento. Este é um herói aniquilado pouco a pouco, que sofre a dimensão de sua bondade e inocência e acaba sendo punido por todos aqueles que convivem com ele, fato que realça seu caráter trágico. $\mathrm{O}$ ponto máximo da destruição do herói acontece quando, depois de ter enfrentado tantas intempéries, Arandir é assassinado por seu sogro Aprígio.

AprígIO (num berro) - De você! (Estrangulando a voz) Não de minha filha. Ciúmes de você. Tenho! Sempre. Desde o teu namoro, que não digo o teu nome. Jurei a mim mesmo que só diria teu nome a teu cadáver. Quero que você morra sabendo. O meu ódio é amor. Por que beijaste um homem na boca? Mas eu direi o teu nome. Direi teu nome a teu cadáver. (Aprígio atira, a primeira vez. Arandir cai de joelhos. Na queda, puxa uma folha de jornal, que estava aberta na cama. Torcendo-se, abre o jornal, como uma espécie de escudo ou de bandeira. Aprígio atira, novamente, varando o papel impresso. Num espasmo de dor, Arandir rasga a folha. E tomba, enrolando-se no jornal. Assim morre.)

AprígIo - Arandir! (mais forte) Arandir! (um último canto) Arandir! (RODRIGUES, 1990, pp. 152-153).

Arandir é o único caso das tragédias cariocas em que o protagonista não é o principal responsável pelo seu próprio aniquilamento, mesmo que, para que isso ocorra, seja necessário que ele cometa um erro trágico. No caso, o beijo no asfalto. Ele e Zulmira estão inseridos em um contexto de mediocridade generalizada, em que o senso comum não aceita qualquer desvio de norma, precisando aniquilar quem foge à regra. O que incomoda, nessas duas peças, é a individualidade que contesta a mediocridade presente no senso comum: “Ele[Arandir] e Zulmira estão anestesiados, mas a vida espreita e ronda em torno. $\mathrm{O}$ conselho da cartomante vigarista e o 
atropelamento do rapaz darão o sinal para que se inicie a descida vertiginosa para a destruição." (FRAGA, 1998, p. 161)

Nas outras três peças do conjunto, o caminho que as personagens seguem é semelhante: elas são absorvidas por uma realidade cruel, frente à qual devem ter atitudes que são levadas ao seu limite. Esses momentos extremados vão encaminhá-las a sua destruição, a uma morte fria, estúpida. As personagens se aniquilam a partir das ações que praticam no decorrer da peça, submetendo-se à tragicidade da vida.

Raul, protagonista de Perdoa-me por me traíres, surge na peça somente a partir do segundo ato, mas ainda no primeiro ato ele é assunto corrente para Glorinha, sua sobrinha. Em meio às suas falas, fica evidente o medo que ela tem do tio, descrito como um homem violento. No segundo ato, Raul surge como o narrador da morte de Judite, mãe de Glorinha e, motivado por ciúmes, ele conta que ofereceu veneno à cunhada por ela ter traído o marido.

Tio Raul (batendo no peito) - Eu a matei! Eu! E olha: ninguém sabe, ninguém! Inclusive minha mãe, meus irmãos, pensam, até hoje, que foi suicídio! (baixo, com um meio riso hediondo) (Cresce) Mas o assassino está aqui e sou eu, o assassino! (arquejando) Segurei a alça, fui ao cemitério e, à beira do túmulo, derramei uma colher de pétalas em cima do caixão. Vê tu? (RODRIGUES, 1985, p. 167).

Durante o terceiro ato, ele volta a ameaçar Glorinha de morte caso ela não lhe revele toda verdade sobre sua vida. $\mathrm{O}$ ato, desenvolvido em uma única cena, leva à máxima tensão a relação entre tio e sobrinha, variando os sentimentos deles entre o amor e oódio. Em alguns momentos, Raul afirma que odeia Glorinha e que vê nela a continuidade das volúpias da mãe. A tensão máxima é alcançada quando Raul revela, momentos antes do desfecho da peça, que amava Judite, e que a matou porque ela nunca pertenceu a ele, apesar de ter pertencido a muitos homens. Confessa, também, que criou Glorinha para si:
Tio RAUL - Glorinha, eu te criei para mim. Dia e noite, eu te criei para mim! Morre pensando que eu te criei para mim! (Os dois levam o copo aos lábios, ao mesmo tempo. Tio Raul bebe de uma vez só. Glorinha ainda não bebeu. Tio Raul cai de joelhos, soluçando.) (IDEM, p. 179).

Tais revelações acarretarão no aniquilamento da personagem, provocado por sua morte. Glorinha, que o havia convidado para morrerem juntos, não bebe o veneno e deixa-o agonizando sozinho, apenas com a companhia de Tia Odete, sua esposa, que perambula pela casa.

Assim como Raul, "Seu" Noronha, de Os sete gatinhos, é o próprio a traçar o caminho da desgraça que deve percorrer até sua morte. $\mathrm{O}$ seu percurso passa da adoração pela filha caçula até a descoberta de sua gravidez, com a queda do mito de Silene. ${ }^{3}$ Depois disso, busca incessantemente pelo homem que chora por um olho só, matando Bibelot, o amante de Silene, equivocadamente. A partir da morte de Bibelot, será descoberto que o homem que chora por um olho só é o próprio "Seu" Noronha, ele que prostitui suas próprias filhas, que se revoltam e o matam a punhaladas.

Durante toda a peça, Noronha é um patriarca que se altera facilmente, ameaça e agride as filhas e a esposa. Ao elevar Silene ao patamar de mito, ele mantém na virgindade dela o pilar da família, impedindo o seu desmoronamento moral. Com a descoberta da gravidez da caçula, ocorre pouco a pouco o declínio de todos os membros da família. Sabe-se que ele, na ânsia de manter a virgindade de Silene, encaminhou homens, deputados e velhos para suas outras filhas, induzindo todas elas à prostituição.

3 O termo "o mito de Silene" é de Marcelo Paulini (1994: p. 9), que comenta em sua dissertação de mestrado: "É importante notar que Noronha é um moralista preso aos valores de sua condição social, e frustrado por não conseguir atingi-los. Procura então compensar sua miséria existencial estabelecendo um mito em sua vida, e na dos demais membros da família: o mito de Silene." 
Quando, finalmente, as filhas percebem que ele é o responsável por todas suas desgraças, resolvem matá-lo, acabar com o homem que as arruinou. Arlete, a filha mais insolente de todas, toma a iniciativa de matá-lo, assim que ela percebe que saem lágrimas apenas de um olho do seu pai, cumprindo-se, então, a previsão do próprio Noronha. Ele, que perseguiu e procurou durante toda a ação da peça por aquele que arruinou a sua família, acaba por traçar ele próprio seu destino de malogro.

Tendo a suspeita de que Bibelot é o homem que procuram, Aurora convida-o para dormir no quarto, armando uma emboscada. Enquanto o jovem dorme, toda a família entra no quarto e Noronha crava o punhal em seu coração. Ao perceberem que Bibelot chora normalmente, as filhas acusam Noronha de cometer assassinato e o acuam, ameaçando-o. Só então, com a pressão das filhas, Noronha chora e percebe-se que suas lágrimas saem por um olho só, revelando-se o verdadeiro responsável pela destruição da família.

(Todos seguem o chefe da família. Entram no quarto. Por um momento, "seu" Noronha olha o rapaz adormecido. Ergue o punhal e o crava, até o cabo, no coração de Bibelot. Este dá um arranco, um uivo estrangulado. Depois, tomba. Arqueja na sua agonia. Aurora cai de joelhos.)

Aurora (num fundo gemido) - Meu amor, perdoa meu ódio!

(Arlete adianta-se.)

ARLETE (sôfrega) - Quero ver a lágrima da morte!

DÉBORA - Morreu!

(Arlete segura o rosto do rapaz.)

Arlete (no seu assombro) - Mas está chorando pelos dois olhos! (na sua histeria) São duas lágrimas!

Hilda (histérica também) - Papai! Não é o homem que chora por um olho só!

ARLETE (crescendo para o pai) Assassino!

(As filhas avançam para o pai, que recua.) (IDEM, p. 251).

Por fim, Guida, de A serpente, última peça escrita por Nelson Rodrigues, também é a única responsável por sua própria destruição, além da destruição do seu casamento. Preocupada com a infelicidade da irmã Lígia, ela resolve compartilhar sua felicidade, oferecendo uma noite com o marido Paulo. Após a consumação do ato, corroída pelo ciúme, Guida desconfia dos dois, persegue-os e tenta evitar encontros entre eles. Sufocado pela perseguição doentia de Guida, Paulo joga a esposa do décimo segundo andar do prédio onde moram.

Para compreender o motivo do ciúme de Guida, faz-se necessário saber que Lígia, sua irmã, era casada com Décio. Após um ano decasamento, eles se separaram porque ele não conseguiu consumar o casamento. Desesperada com a situação em que se encontra, Lígia pretende se matar. É neste momento que surge a proposta de Guida. $\mathrm{O}$ que acontece em seguida é que Guida observa entre o marido e a irmã certo envolvimento e resolve, então, proibirlhes as saídas em horas comuns e evita que eles se comuniquem no apartamento onde moram. São essas atitudes que provocam seu desfecho de malogro, já que tendo sufocado a própria relação com o marido, impede que ele a deseje como mulher e, em seguida, a assassine. Antes de morrer, no entanto, Guida já havia destruído toda a relação existente com sua irmã, acusando-a de traição.

LíGIA - Te direi tudo. Tens um marido que te faz feliz, e segundo você própria, a mais feliz das mulheres. Eu tenho um marido que me destruiu. Não sou mais nada. E põe na tua cabeça, criatura, que eu não fiz nada. Só fiz o que você mandou. Foi você que disse: - "Vai". Eu ia morrer e seria tão fácil morrer. Mas você, você me salvou e disse: - "Te dou uma noite do meu marido". Eu tive esta noite. Só. E queres me tirar esta noite? Agora é tarde. Tudo já aconteceu.

GUIDA - Acabaste?

LíGIA - Acabei. Não quero ouvir nada de você.

GuIDA - Pois ouve ainda. Você não pode pensar, ou olhar, ou tocar meu marido. Ou sorrir. A gente não sorri para todo mundo. Você não pode sorrir para meu marido. Escuta, Lígia. Você não me conhece. Paulo não me conhece, eu 
própria não me conhecia. Eu me conheço agora. Se você quiser mais do que a noite que já teve, eu mato você. Ou então, mato o único homem que amei. (Com ar de louca) Paulo dormindo e morrendo. (RODRIGUES, 1990, p. 75-76).

\section{Expressionistas?}

As tragédias cariocas não são, pois, peças expressionistas em sua totalidade. Possuem alguns resquícios daquilo que é denominado expressionismo. Não necessariamenteoexpressionismodopósguerra alemão, mas um expressionismo como tendência estética, de demonstrar um fato real da sociedade pela distorção, pelo grotesco, pela agressividade. $\mathrm{O}$ dramaturgo se aproxima dessa estética pelo uso frequente de elementos do grotesco, sobretudo aqueles que ressaltam um quotidiano em decadência das personagens, o que também ajuda a rebaixá-las e aproximá-las de um tom cômico. Mesmo assim, a a proximação com a vanguarda não foi um ponto que tenha percorrido o teatro de Nelson Rodrigues em seu último ciclo. Essas peças são, evidentemente, agressivas. No entanto, dentro dessa agressividade camuflada pelo farsesco, por vezes levada ao melodramático pelo exagero, um ponto que chama a atenção é a tendência do herói em ser carregado pelas situações ao seu aniquilamento. Seja qual for a forma como isso acontece, pelo intermédio de outras personagens da peça ou não, se conscientemente ou não, o fato é que o sentido trágico sempre acompanha os heróis rodriguianos, da mesma maneira como acompanha, também, os heróis expressionistas.

\section{Referências bibliográficas}

BLEDSOE, Robert Lamar. The expressionism on Nelson Rodrigues: a revolution in Brazilian drama. Michigan: Microfilmed by University of Wisconsin, 1971.
CASALS, Josep. El expresionismo. Barcelona: Montesinos, s.d.

FRAGA, Eudinyr. Nelson Rodrigues expressionista. Cotia: Ateliê Cultural, 1998.

LIMA, Mariângela Alves de. Dramaturgia expressionista. In: GUINSBURG, J. O expressionismo. São Paulo: Perspectiva, 2002.

MEDEIROS, Elen de. Nelson Rodrigues $e$ as tragédias cariocas: um estudo das personagens. 2005. 180 p. Dissertação (Mestrado em Teoria e História Literária) - Instituto de Estudos da Linguagem, Unicamp, Campinas.

PALMIER, Jean-Michel.L'expressionnismo et les arts. Paris: Payot, 1979.

PAULINI, Marcelo M. Peccioli. Alguns aspectos da dramaturgia de Nelson Rodrigues. 1994. 132 p. Dissertação (Mestrado em Teoria e História Literária) - Instituto de Estudos da Linguagem, Unicamp, Campinas.

RODRIGUES, Nelson. Teatro completo de Nelson Rodrigues. vol. 3. Rio de Janeiro: Nova Fronteira, 1985.

Teatro completo de Nelson Rodrigues. vol.4. Rio de Janeiro: Nova Fronteira, 1990.

ROSENFELD, Anatol. História da literatura e do teatro alemães. São Paulo: Perspectiva/ Edusp; Campinas: Editora da Unicamp, 1993. 